\title{
Acknowledging our Past Editor
}

I approach my first issue as editor of the journal Arctic with great trepidation, not only because this venerable publication has, for almost 80 years, published the works of some of the greatest Arctic scientists and social scientists, but also because I am following in the footsteps of Karen McCullough, an extraordinarily competent editor, whose example is simultaneously an inspiration and the source of my apprehension. Many of the journal's authors and readers are familiar with Karen's editorial work, but few know how Karen's background prepared her for working on this multidisciplinary Arctic publication. As she departs from the front of house at the Arctic Institute of North America, I would like to share a little about how Karen became such a brilliant editor.

Karen studied archaeology, a discipline that borrows ideas from other disciplines and searches them for answers to questions about what motivated people in the past. Knowledge of geomorphology, palaeoenvironments, animal ecology, ocean currents, and of course social sciences was a necessary part of any archaeological scholar's interest in contextualizing human intentions. In 1978, while completing her MA on Iroquoian history at the University of Calgary, Karen spent her first field season in the Arctic. In the Bache Peninsula region of Ellesmere Island, she discovered some of the earliest pre-contact Inuit (Thule) settlements, and she went on to spend 15 seasons in the region surveying and excavating sites. The early years of this work formed the basis of her $\mathrm{PhD}$ research, which had a significant impact on our understanding of when the Inuit first settled the eastern Arctic, the nature of that settlement, and their initial contact with Europeans. Some of this work, including The Ruin Islanders: Early Thule Culture Pioneers in the Eastern High Arctic (1989), was published by the Canadian Museum of History. One long-term result of Karen's research was the building of strong and enduring cooperation with Danish colleagues in Greenland.

As researchers working in the Arctic are aware, safe and productive fieldwork is largely dependent on excellent planning and organization. Karen's many years in a particularly remote and demanding region were a great success because of her meticulous attention to detailed planning, not only for equipment needs, but to ensure the physical comfort of her fellow crew members. Travel to these regions was difficult and expensive, so a safe, happy, and consequently, productive crew was guaranteed through her exceptional organizational skills.

This familiarity with the Arctic and the many disciplines through which it is understood, as well as her remarkable organizational skills, contributed to Karen's excellence as the editor of Arctic. She filled this role for almost 30 years, poring over every paper and ensuring grammatical clarity and broad accessibility by remaining attentive to the journal's multidisciplinary nature. She carefully sought out excellent, fair reviewers to maintain the high standard of the journal, the impact of which grew significantly over her career, doubling in the last 20 years. Authors often expressed gratitude for her skill and attention, acknowledging the valuable contributions she made to their published work. In reaction to her retirement, one author recently wrote, "It's been reassuring, enlightening and rewarding to publish papers in Arctic over the years, and I remain impressed by your unwavering standards, attention to detail, prompt attention to emails and papers, respect, updates, and the list goes on."

While Karen communicated frequently with many scholars over the decades, few have had the opportunity to get to know her. Many may have imagined that after a long and outstanding career, Karen would relax into a quiet retirement. And while there is certainly going to be more relaxation as the stresses of deadlines fall away, readers would be mistaken to imagine Karen as a slow-moving retiree. In fact, Karen is a remarkable athlete and, I am sure you would not be surprised to learn, has a great interest in the natural world. She participates in high-intensity weight lifting and cardiovascular exercises and competes as a dragon boat racer, impressive in anyone half her age. She balances these pursuits with less strenuous activities, including yoga, birdwatching, and hiking. And while I am relieved and grateful that she will remain with the journal as a consultant, Karen's busy life is likely to expand. She is excited to get involved with her community choir and will continue to travel widely. I join her colleagues at the Arctic Institute of North America, the many authors she has met, and her family and friends in wishing her a long and healthy retirement and congratulating her on an outstanding career, during which she has earned the respect and affection of countless authors. 